\title{
A matemática e a inter-relação com a educação ambiental: um projeto de formação de professores
}

\section{Mathematics and the inter-relation to education environmental: a teacher training project}

Cláudio Cristiano Liell

Arno Bayer

\section{Resumo}

O presente estudo parte de uma pesquisa de doutorado, analisa as implicações de um trabalho de formação continuada de 80 horas em educação ambiental e matemática para oito professores de matemática das séries finais do ensino fundamental das redes municipal e estadual de São Sebastião do Caí, RS. De acordo com os resultados, é possível perceber que a formação deu subsídios aos professores para um trabalho com a temática ambiental, por meio de construções de atividades que originaram projetos interdisciplinares e que foram desenvolvidas nas aulas desses professores. Este artigo está fundamentado principalmente nas ideias de: L. Carvalho (2001), I. Carvalho (2012), Lima (2009), Guimarães (2000), Coll (2006), Skovsmose (1994), Penteado (2010), Schön (2000) e Behrens (1996). Com o trabalho da temática ambiental nas escolas, os alunos se sentiram incentivados a participar com entusiasmo das aulas de matemática, os professores destacaram que os temas abordados contextualizaram os conteúdos matemáticos, e foi possível desenvolver a consciência ambiental de todos os envolvidos no processo.

Palavras-chave: Formação em educação ambiental. Matemática. Temas ambientais.

\section{Abstract}

This study, part of a doctoral research, analysis the implications of an 80-hour continuing education in environmental education and mathematics to eight math teachers in the upper grades of municipal and state elementary schools from São Sebastião do Caí, RS. According to the results, it was possible to notice that the training gave grants to teachers to work with the environmental theme, through building activities that originated interdisciplinary projects that were developed in the classes of those teachers. This paper is mainly based on the ideas of: L. Carvalho (2001), I. Carvalho (2012), Brugger (2004), Lima (2009), Guimarães (2000), Coll (2006), Skovsmose (1994), Penteado (2010), Schön (2000) e Behrens (1996). Through the work of environmental theme in schools, students felt encouraged to participate with enthusiasm in math classes, the approached themes contextualized the mathematical subjects and it was possible to develop the environmental awareness of everyone involved in the process.

Keywords: Environmental themes. Formation on environmental education. Mathematics.

Recebido em 16/10/2017 - Aprovado em 13/02/2018

http://dx.doi.org/10.5335/rep.v25i2.8173

Doutor em Ensino de Ciências e Matemática pela Ulbra. Professor das Faculdades Anhanguera, Cesf e Famur. E-mail: cristianoliell@hotmail.com

** Doutor em Educação pela Universidad Pontificia de Salamanca (1997). Professor titular da Ulbra e professor orientador de mestrado e doutorado no Programa de Pós-Graduação em Ensino de Ciências e Matemática (PPGECIM). E-mail: bayerarno@yahoo.com.br 


\section{Introdução}

Com a modernização, o homem passou a ter um estilo de vida que o levou à formação de um mundo com desequilíbrios, o que gerou degradação ambiental e social, e não há consenso sobre como construir um desenvolvimento que integre justiça social, sustentabilidade ambiental e viabilidade econômica.

As perspectivas sobre o nosso futuro e o do planeta não são nada animadoras. Para D’Ambrósio, "a sobrevivência da Terra está ameaçada, tornando-se uma preocupação central e imediata. A situação atual exige medidas urgentes em todos os setores - científico, cultural, econômico e político -, além de uma maior sensibilização de toda a humanidade" (1997, p. 49).

A educação tem um papel primordial nesse sentido, pois pode contribuir decisivamente com ações pedagógicas e com modelos de ensino que atendam às modificações que a sociedade passou a exigir e que visem à formação de alunos capazes de refletir sobre questões socioambientais.

A sala de aula pode ser utilizada como um espaço para disseminação da consciência ambiental. De acordo com os Parâmetros Curriculares Nacionais (PCNs), a UNESCO, em 1968, fez um estudo comparativo, respondido em 79 países, sobre o trabalho desenvolvido pelas escolas com relação ao meio ambiente, no qual foi formulada a proposição de que a educação ambiental não deve se constituir numa disciplina, mas em um tema a ser abordado de forma transversal em todas as disciplinas do currículo escolar.

Os autores deste estudo, em contatos com professores de matemática, observaram que a maioria compartilha, em reuniões e em momentos de descanso, as angústias e as dificuldades sobre como tratar o tema transversal meio ambiente em suas aulas. Parece que esses profissionais estão motivados a contribuir com a formação dos alunos, a fim de que estes adotem um estilo de vida e caminhos em que o respeito pelo funcionamento e pelos limites da natureza está presente. Porém, deparam-se com falta de formação na área para o desenvolvimento de um trabalho efetivo.

A problemática levantada envolve uma tese de doutorado que se norteou pelo seguinte questionamento: uma formação continuada em educação ambiental e em educação matemática pode influenciar nas práticas de sala de aula sobre a temática ambiental dos professores de matemática e contribuir para o desenvolvimento da consciência ambiental nos alunos?

Considerando o contexto mencionado, o foco deste trabalho é mostrar como uma formação continuada de 80 horas em educação ambiental e matemática, desenvolvida para oito professores de matemática das escolas públicas do município de São Sebastião do Caí, RS, influenciou nas práticas de sala de aula sobre a te- 
mática ambiental desses professores e contribuiu para o desenvolvimento da consciência ambiental nos alunos. São também abordadas as atividades desenvolvidas durante a formação, a percepção dos professores participantes referente à aplicação das tarefas construídas em sala de aula e a aprendizagem do conhecimento matemático e sua relação com os temas ambientais.

\section{Formação de professores}

Os educadores necessitam se qualificar constantemente, para que possam repensar a sua prática docente e para que não entendam essa necessidade como algo burocrático a cumprir, cobrado pelas mantenedoras que administram as instituições de ensino em que lecionam.

De acordo com os PCNs, repensar a prática docente é uma tarefa que necessita ser realizada constantemente pelos educadores.

A prática de todo professor, mesmo de forma inconsciente, sempre pressupõe uma concepção de ensino e aprendizagem que determina a compreensão dos papéis de professor e aluno, da metodologia, da função social da escola e dos conteúdos a serem trabalhados. A discussão dessas questões é importante para que se explicitem os pressupostos pedagógicos que subjazem à atividade de ensino, na busca de coerência entre o que se pensa estar fazendo e o que realmente se faz (BRASIL, 1997, p. 30).

Os PCNs enfatizam o papel do professor nesse processo, pois

[...] a ele cabe apresentar os conteúdos e atividades de aprendizagem de forma que os alunos compreendam o porquê e o para que do que aprendem, e assim desenvolvam expectativas positivas em relação à aprendizagem e sintam-se motivados para o trabalho escolar (BRASIL, 1997, p. 48).

Segundo Zabalza (2004), a formação de professores, para ser eficiente, tem que ser contínua, tomada como um processo realizado ao longo da vida e não limitada aos anos de estudo na universidade.

Acredita-se que alguns educadores ainda resistam à ideia de refletir sobre sua própria prática, considerando que as orientações recebidas nos cursos de formação inicial são suficientes, enquanto outros buscam incessantemente aperfeiçoar seu exercício profissional e promover mudanças significativas no processo que exige a preparação de um sujeito ativo, dinâmico e empreendedor.

Para Ghedin, Leite e Almeida (2008), é preciso repensar a formação de professores a partir do contexto de seu trabalho, e essa formação não pode estar distante da reflexão crítica acerca da sua realidade. É necessário estar atento a essa dimensão por meio de propostas curriculares que possibilitem o entendimento da dinâmica e das relações desse ambiente com o professor. 
Nos desafios da atualidade escolar, é importante que o professor adote uma postura questionadora e investigue a sua própria ação. A pesquisa e o estímulo ao seu desenvolvimento junto com as atividades docentes precisam ser fomentados, para que contribuam, conforme Elliott (1998) e Lüdke (2001), no enfrentamento dos problemas educacionais, de modo especial, os vivenciados pelos professores e pelos seus alunos nas escolas.

\section{As práticas do professor de matemática com a temática ambiental}

As mudanças na prática pedagógica entre os docentes acabam sendo pouco discutidas, em especial, entre os professores de matemática. Muitas leituras indicam que isso ocorre devido a uma formação ou especialização que não amplia seu campo de investigação para além das fronteiras do saber disciplinar. Esse pensamento é corroborado por Cifuentes e Prestini (2006), quando afirmam que essa dificuldade decorre da própria formação do professor, uma vez que "os professores têm que pensar e colocar em prática uma proposta que eles próprios não vivenciaram em momento algum de suas vidas" (2006, p. 46).

Para Costa (2009), há um déficit na formação dos educadores nos cursos de licenciatura para o trabalho com a educação ambiental, e a solução estaria em fornecer aos professores uma formação por meio da ambientalização curricular da educação ambiental.

Para formarmos profissionais do ensino com um fazer pedagógico que se lance para além dos limites do pensamento cartesiano, é necessário, primeiramente, que esses profissionais estejam dispostos a reconstruir suas ideias e, segundo Cifuentes e Prestini (2006), trabalhar em uma perspectiva transversal.

Os PCNs sugerem que a matemática tenha um caráter transversal, quando propõem que essa ciência pode auxiliar na compreensão de temas transversais, entre eles, o estudo do meio ambiente, foco deste trabalho.

Penteado (2010) sugere, como formação ao professor que deseja trabalhar com o tema meio ambiente em suas aulas, que, inicialmente, desenvolva uma consciência ambiental e mude da visão capitalista de compreensão de mundo para uma forma mais satisfatória de resolver as questões da sobrevivência humana. Assim, terá condições de mudar a maneira de realizar o trabalho escolar que, de informativo, passará a ser essencialmente formativo.

Dentro desse contexto, faz-se necessária uma formação que leve o professor a considerar a matemática de uma forma mais significativa, em que a interação com outras disciplinas (interdisciplinaridade) e com temas do dia a dia faça com que 
ela transcenda a ideia de uma ciência isolada, para uma ideia mais abrangente, relacionando questões mais amplas e refletindo sobre situações do nosso cotidiano.

A proposta de Skovsmose (1994) traz como propósito a possibilidade de os educandos atingirem a consciência crítica. Para tal, a educação matemática necessita, além de proporcionar uma alfabetização matemática voltada para o entendimento das influências que a disciplina exerce nos meios científico, tecnológico e social, ter uma abordagem que articule os conhecimentos entre si de forma reflexiva.

Para Búrigo,

[...] a perspectiva crítica se apresenta como um referencial que dá sustentação para a relação entre a Educação Ambiental e a Educação Matemática marcada pela consciência de que os grupos étnicos têm suas peculiaridades de conhecimento que são parte fundamental da aprendizagem de conceitos matemáticos, em suas formas abstratas ou práticas, teóricas ou concretas, úteis de imediato ou em longo prazo (2009, p. 84).

O professor, alinhado com a perspectiva de trabalho sugerida, estará exercendo um trabalho que visa à cidadania, o que é anunciado nos PCNs como um trabalho que dialoga com a transversalidade e a interdisciplinaridade. Além disso, a degradação ambiental pode ser objeto de estudo numa perspectiva inter e transdisciplinar em que os conhecimentos matemáticos podem ser trabalhados, e a formação da consciência crítica dos alunos possa ser desenvolvida.

O trabalho do professor com a informação em sala de aula não deve, de acordo com I. Carvalho (2012), limitar-se ao "saber acumulado" e de alguma forma sancionado, reconhecido, legitimado, mas pode aconselhar e incentivar a coleta de informações diretamente no meio ambiente com o qual professores e alunos passam a lidar a partir da sala de aula, por meio de comportamentos participativos gerados e organizados.

Para a autora, essa nova forma de trabalhar em sala de aula permite aos estudantes: serem sujeitos do processo; desenvolverem a condição de ouvir o outro; refletirem a partir do saber existente em direção à construção constante do saber; perceberem o professor como organizador e coordenador do processo; enfim, construírem uma cultura do saber e do saber fazer com o saber.

Para Lima (2009) e Loureiro (2004), os educadores necessitam assumir uma postura de reflexão crítica, que permita práticas transformadoras e criativas, cujo resultado é a construção de uma nova sociedade, que seja democrática, responsável, igualitária e sustentável, uma educação ambiental crítica e emancipatória.

Nesta visão o educando e o educador são agentes sociais que atuam no processo de transformações sociais; portanto, o ensino é teoria/prática, é práxis. Ensino que se abre para a comunidade com seus problemas sociais e ambientais, sendo estes conteúdos de trabalho pedagógico. Aqui a compreensão e a atuação sobre as relações de poder que permeiam a sociedade são priorizadas, significando uma educação política (GUIMARÃES, 2000, p. 17). 


\section{Metodologia, descrição e resultados do estudo}

O presente estudo parte de uma pesquisa de doutorado, que resultou de uma formação continuada de 80 horas (Figura 1) em educação ambiental e matemática, proporcionada a oito professores de matemática e seus respectivos alunos de 5 escolas municipais e estaduais do município de São Sebastião do Caí, nos anos de 2014 e 2015. Teve o objetivo de verificar se o desenvolvimento dessa formação traria mudanças na concepção de educação ambiental dos professores envolvidos e contribuiria para o desenvolvimento da consciência ambiental nos alunos.

Os professores responderam a dois instrumentos de pesquisa (Questionários 1 e 2), para analisar as opiniões referentes ao trabalho com o tema transversal meio ambiente nas suas aulas e verificar se a formação oportunizada deu subsídios para o trabalho com a temática. O Questionário 1 foi aplicado no início do curso e o Questionário 2 no término da formação.

Figura 1 - Formação continuada de 80 horas

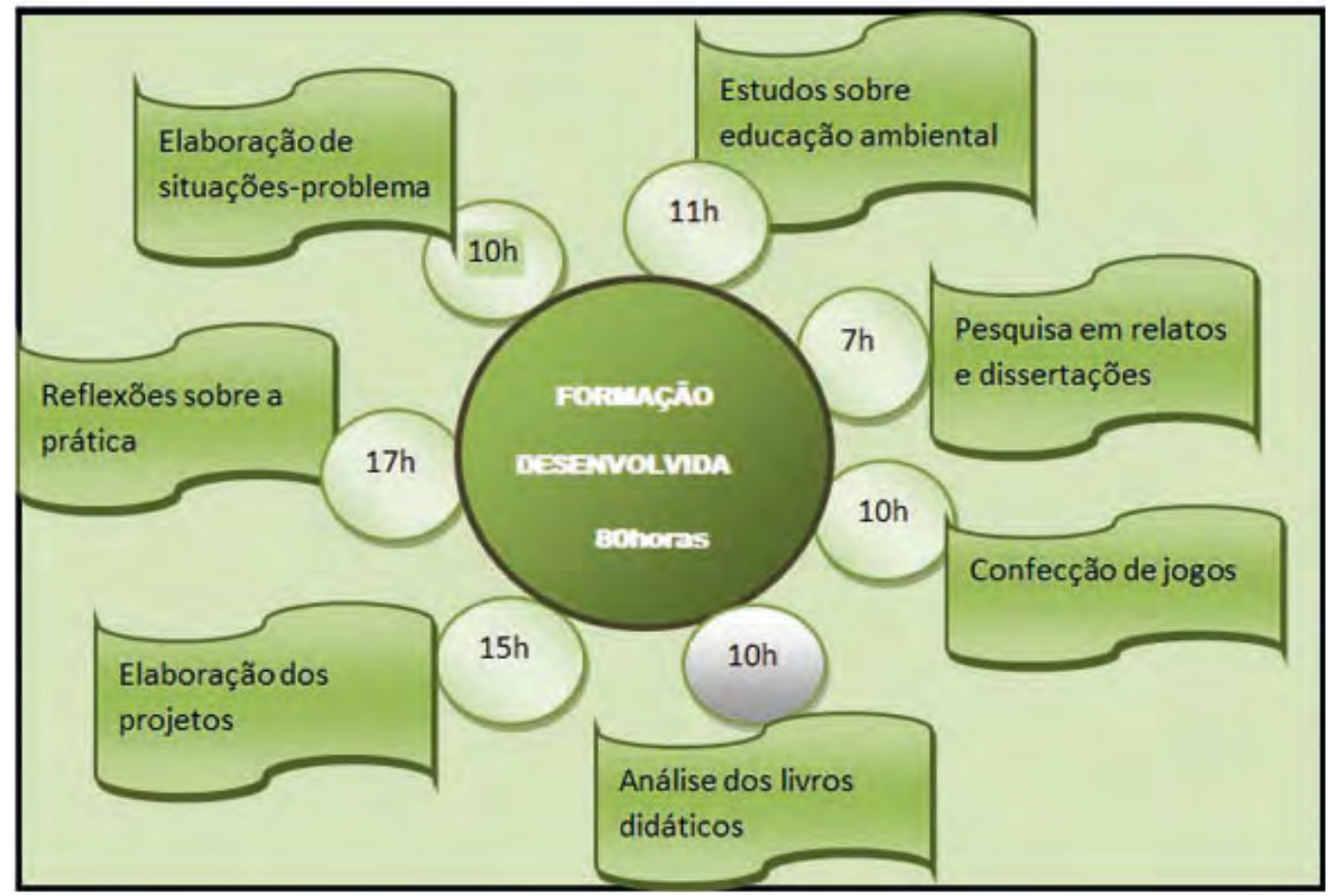

Fonte: elaboração dos autores. 
Os professores de matemática envolvidos na formação, o número de alunos e as turmas foram distribuídos conforme o Quadro 1:

Quadro 1 - Sujeitos da pesquisa

\begin{tabular}{|c|c|c|}
\hline Professor & Número de turmas & Número de alunos \\
\hline S1 & 3 & 75 \\
S2 & 2 & 40 \\
S3 & 2 & 40 \\
S4 & 3 & 70 \\
S5 & 3 & 76 \\
S6 & 2 & 40 \\
S7 & 3 & 70 \\
S8 & 1 & 20 \\
\hline
\end{tabular}

Fonte: elaboração dos autores.

A formação iniciou no ano de 2014. Das 80 horas de curso, 50 foram ministras em 2014, e 30, em 2015, por meio de encontros mensais orientados pelos autores deste estudo, com o objetivo de proporcionar uma formação que desse subsídios para um trabalho com a temática ambiental nas aulas de matemática.

No primeiro encontro da formação, em março de 2014, os professores participantes responderam ao Questionário 1; sob a orientação do primeiro autor deste artigo, foram levados a responder sobre suas concepções de educação matemática e educação ambiental e suas práticas pedagógicas no que diz respeito à temática ambiental.

De acordo com as respostas, apenas um dos professores envolvidos respondeu que, eventualmente, na sua prática pedagógica, promovia a relação entre educação matemática e educação ambiental e exemplificou dizendo que relacionava o tema "água" com regra de três, pedindo aos alunos que anotassem o tempo que ficavam no banho para calcular a quantidade de litros de água desperdiçados. Os demais afirmaram não trabalhar com temas ambientais nas aulas, argumentando que se sentiam despreparados.

Os professores estavam sensibilizados e conscientes da necessidade e da importância do tratamento dessa questão com seus alunos, mas alegaram que não abordavam o tema porque necessitavam de uma formação que os preparasse para o desenvolvimento de atividades referentes à questão ambiental $\square$ opinião compartilhada por todos os participantes. De acordo com L. Carvalho (2001), o importante a ser percebido pelos educadores é que não existem fórmulas prontas para o desenvol- 
vimento de práticas educativas relacionadas à temática ambiental. Com reflexões cuidadosas e escolhas conscientes entre diferentes possibilidades de avaliações sistemáticas e inovações criativas, novas perspectivas de ensino poderão ser traçadas.

Para L. Carvalho (2001), o professor está consciente da necessidade e da importância do tratamento da questão ambiental com seus alunos, mas precisa estar preparado e instrumentalizado para enfrentar esse desafio. $\mathrm{O}$ autor argumenta que a formação inicial de professores poderia investir em uma estrutura curricular muito mais flexível e dinâmica, que facilitasse o tratamento das questões ambientais nos diferentes cursos de licenciatura por meio de experiências diversificadas e de uma abordagem que envolvesse os vários aspectos desse tema. Já, para atividades de formação contínua, o autor destaca que cabe às instituições responsáveis pela educação no país, em articulação com outros setores sociais, oferecer aos professores diferentes oportunidades e possibilidades de dar continuidade à sua formação, desde que enriqueçam suas experiências como educador com criatividade e flexibilidade.

No mês de abril, foi realizado o segundo momento da formação, e, nesse encontro, os professores reuniram-se para fazer um estudo dos livros didáticos das séries finais do ensino fundamental utilizados pelos alunos e também dos que serviam de referência para planejamento das aulas, com o objetivo de investigar a frequência com que o tema ambiental aparecia nesses materiais, a forma como a temática era tratada nos livros e os conteúdos matemáticos que mais exploravam o tema.

$\mathrm{Na}$ pesquisa realizada nos livros didáticos, verificou-se que a presença de temas ambientais nos livros didáticos do ensino fundamental é quase inexistente, ou seja, aparece em apenas $0,62 \%$ das páginas. Os conteúdos matemáticos que mais exploraram o tema transversal meio ambiente nos livros são estatística, porcentagem e regra de três. $\mathrm{O}$ desmatamento e o consumo de energia elétrica são os temas mais recorrentes nos livros, aparecendo em mais de $50 \%$ das páginas com a temática ambiental.

O momento seguinte da formação ocorreu em maio, quando foram realizados estudos em livros, revistas e meios eletrônicos sobre a perspectiva da educação ambiental crítica e emancipatória, que utiliza ações participativas, interdisciplinares e sustentáveis, e em relatos de experiência que exploram a temática ambiental nas aulas de matemática, para o embasamento da investigação e da elaboração de propostas de trabalho.

No mês de junho, foi realizada uma conferência virtual envolvendo os professores participantes da formação e 19 estudantes universitários do curso de formação de professores de matemática da Pädagogische Hochschule Karlsruhe (Escola Pedagógica de Karlsruhe), Alemanha, por meio de um intercâmbio cultural promovido pelo Programa de Pós-Graduação em Ensino de Ciências e Matemática 
da Universidade Luterana do Brasil. Os objetivos foram: verificar e discutir como o tema ambiental é trabalhado nas aulas de matemática do ensino básico no estado de Baden Württemberg, Alemanha; averiguar como a temática ambiental aparece nos livros didáticos de matemática; e trocar experiências pedagógicas para o enriquecimento das propostas de trabalho que seriam elaboradas.

Pela pesquisa realizada pelos universitários em Karlsruhe e pelos dados compartilhados na conferência virtual entre professores do Brasil e acadêmicos da Alemanha, constatou-se que o tema ambiental aparece com pouca frequência nos livros didáticos de Baden Württemberg ( $3,36 \%$ das páginas) e é quase inexistente, conforme dito anteriormente, nos livros brasileiros para o ensino fundamental pesquisados.

Em julho e agosto, os professores criaram dezenas de problemas matemáticos envolvendo questões ambientais locais e regionais, para serem utilizados, entre os meses de outubro e dezembro, em projetos interdisciplinares envolvendo temas ambientais. Foram criados 80 problemas matemáticos abrangendo as temáticas água, resíduos, poluição, vegetação, fauna, energia e áreas. A Figura 2 ilustra um momento da formação em que as situações-problema foram construídas.

Figura 2 - Elaboração de problemas matemáticos

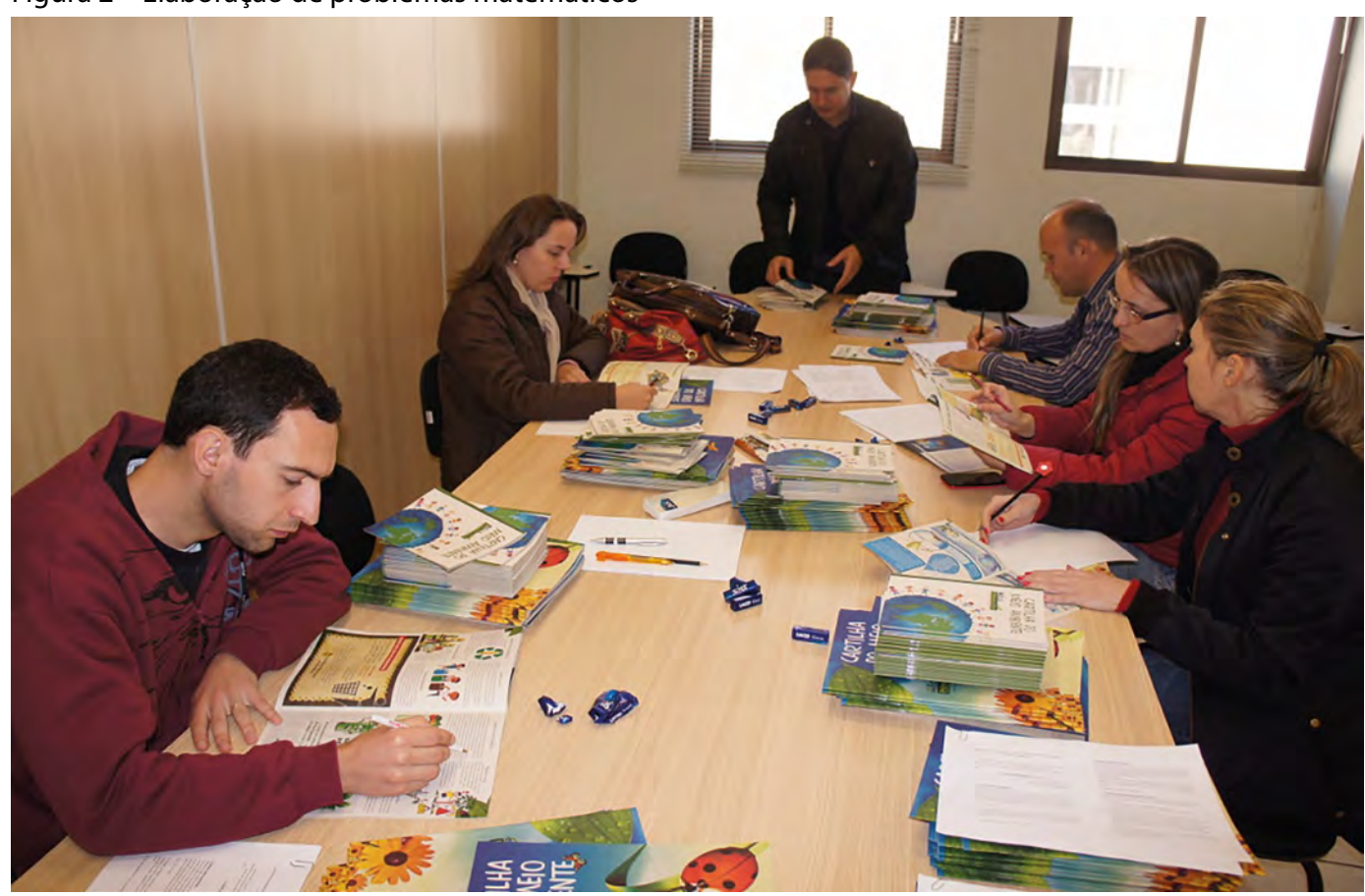

Fonte: elaboração dos autores. 
Em setembro, os professores se reuniram para a elaboração de jogos matemáticos com questões e desafios tratando da temática ambiental. Nesse encontro, os professores criaram cinco jogos, assim denominados: Envelopes Sustentáveis, Cobra Sustentável, Jogo do Einstein Ecológico, Dominó Ambiental e Jogo da Velha Ambiental.

A última etapa da formação de 2014, realizada de outubro a dezembro, foi a organização de projetos interdisciplinares com atividades que integrassem o conhecimento matemático e o meio ambiente e envolvessem, ainda: os jogos e os problemas matemáticos desenvolvidos; pesquisas de campo e pesquisas bibliográficas em órgãos públicos, em organizações não governamentais e na internet, para levantamento dos problemas ambientais locais; interação entre as diversas turmas da escola, com ações envolvendo a preservação do meio em que os alunos vivem; recursos de informática; redações; mostras e materiais manipulativos.

Para Hernández e Ventura, "[...] os projetos geram um alto grau de autoconsciência e de significatividade nos alunos com respeito à sua própria aprendizagem [...]" (1998, p. 72), em outras palavras, o trabalho com projetos desperta o interesse dos alunos e dá significado ao trabalho desenvolvido e sentido ao conhecimento produzido.

Os projetos definidos durante a formação foram elaborados para promover uma aprendizagem interdisciplinar que levasse os alunos a ampliar os significados dos conteúdos estudados, principalmente no que diz respeito ao uso do conhecimento escolar em situações fora da escola, e, principalmente, a alertar para as questões ambientais. Eles exploraram preservação da fauna e da flora, produção de resíduos sólidos, poluição, área de preservação permanente, recursos hídricos e energia. Os conteúdos matemáticos envolvidos na abordagem das temáticas foram estatística, regra de três, porcentagem, proporção, operações com números naturais, perímetro, áreas e medidas de comprimento, massa e volume.

Em março de 2015, a formação foi reiniciada com um encontro para a organização da aplicação dos projetos (Quadro 2) a partir de abril daquele ano, em que foram delimitados os períodos de aplicação, as séries em que seriam aplicados, bem como as escolas e os professores responsáveis pelos projetos. Nesse momento, também foi definida a participação dos professores como cursistas e apresentadores no XII Encontro Gaúcho de Educação Matemática (Egem), realizado no mês de setembro na Pontifícia Universidade Católica do Rio Grande do Sul, por meio do minicurso Projetos Interdisciplinares: uma alternativa para o trabalho com temas ambientais nas aulas de matemática. ${ }^{1}$ 
Quadro 2 - Escolas participantes

\begin{tabular}{|l|l|l|}
\hline \multicolumn{1}{|c|}{ Escolas } & \multicolumn{1}{c|}{ Projetos } & \multicolumn{1}{c|}{ Professores } \\
\hline Escola Municipal Gen. David Canabarro & Energia, resíduos, vegetação, áreas e água & S1 e S2 \\
\hline Escola Municipal Gen. São José & Energia, vegetação, poluição e áreas & S3 e S4 \\
\hline Escola Municipal Alencastro Guimarães & Poluição, água, vegetação e resíduos & S5 \\
\hline Escola Municipal Dr. Alberto Pasqualini & Resíduos, fauna e energia & S6 \\
\hline Escola Estadual São Sebastião & Resíduos e áreas & S7 \\
\hline Escola Estadual Felipe Camarão & Vegetação & S8 \\
\hline
\end{tabular}

Fonte: elaboração dos autores.

O trabalho com a temática ambiental nas aulas de matemática ministradas no município de São Sebastião do Caí virou manchete nos principais jornais da cidade. Foram divulgadas matérias significativas nos jornais Primeira Hora, nos dias 2 de abril e 4 de junho de 2015 (conforme Figura 3), e A Folha, no dia 26 de junho de 2015, ambos com circulação regional, abrangendo seis municípios.

Figura 3 - Repercussão dos projetos envolvendo a temática ambiental

\section{Escolas desenvolvem projetos envolvendo Meio Ambiente e Matemática}

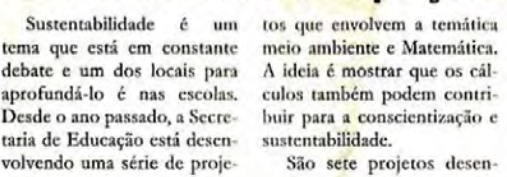

volvendo uma série de proje

\section{Projeto Vegetação da Escola}

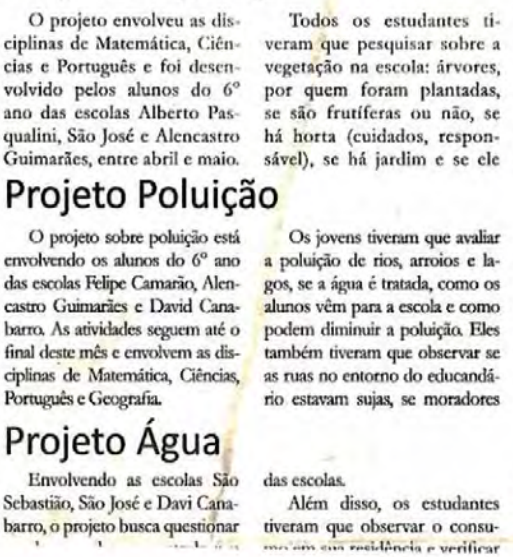
volvidos juntamente com os
professores do município,
envolvendo áreas como ener-
gia, água, resíduos, fauna,
poluição e vegetaçâo. Bstão
participando da atividade as
escolas Alberto Pasqualini,

é usado, tempo de regamento das plantas. Após a pesquisa, os alunos precisaram responder um questionário, com perguntas sobre o assunto, além de realizarem atividades sobre o tema.

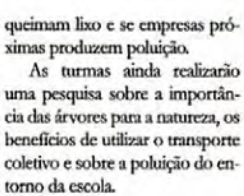

zando tabelas para fazer a previsão de consumo do dia, mès e ano na escola e casas Após a monclusão da pesquísa e tabelas.
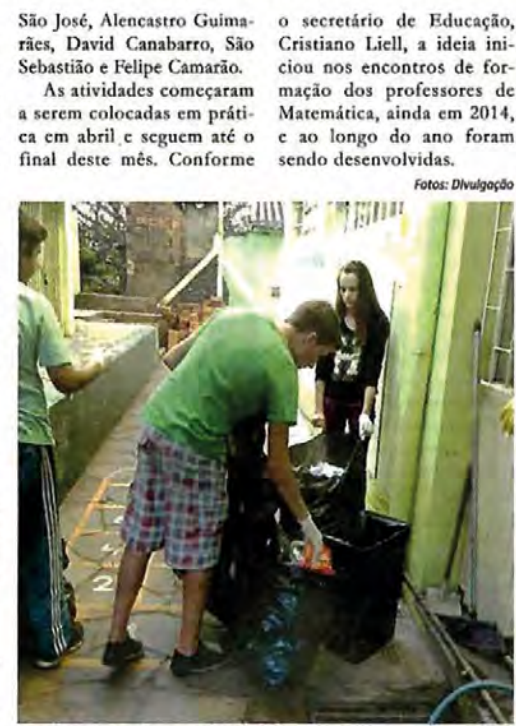

Separaçðo de flixo: alunos da Davi Canabarro separaram o laxo na escola

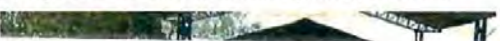

Fonte: jornal Primeira Hora. ${ }^{2}$ 
Ao longo da formação, também foi elaborado um instrumento para avaliar as atividades desenvolvidas com temas ambientais, denominado Ficha Síntese de Observação de Turma. Esse instrumento foi utilizado por cada professor ao longo do desenvolvimento dos projetos, para que se pudesse avaliar os envolvidos e realizar análises referentes ao interesse em aula, à aprendizagem, à formação da consciência ambiental e às dificuldades dos alunos.

Em maio, junho e julho do mesmo ano, ocorreram encontros mensais para troca de ideias sobre o desenvolvimento dos projetos, destacados na Figura 3. Nesses momentos, os professores realizaram reflexões e discussões sobre as práticas desenvolvidas em cada projeto, para que pudessem realizar ajustes, expor as dificuldades e acrescentar novas construções para aprimoramento das atividades executadas com os alunos.

Nos dias 10, 11 e 12 de setembro, os integrantes do curso de formação participaram do XII Egem na PUCRS; o momento mais aguardado do evento pelos educadores foi o sábado à tarde, em que conduziram o minicurso sobre os projetos que tinham desenvolvido até o momento. Para eles, a ocasião foi única, e, pela primeira vez, estavam à frente de uma atividade como pesquisadores, divulgando práticas inovadoras no campo da educação matemática e problematizando o papel do professor de matemática frente às atuais demandas do ensino e da sociedade.

\section{Análises e discussões referentes à formação desenvolvida e o desenvolvimento dos projetos}

As considerações a seguir referem-se aos dados coletados na Ficha Síntese de Observação de Turma e na aplicação do Questionário 2.

Para todos os professores, o interesse dos alunos nas aulas de matemática aumentou consideravelmente, pois, com os projetos interdisciplinares desenvolvidos, os alunos estavam sendo despertados para situações ambientais bastante significativas dentro e fora da escola.

Os professores concluíram que, com o desenvolvimento dos projetos, os alunos compreenderam melhor os conteúdos trabalhados e perceberam a necessidade de reformular os hábitos e cuidados com o meio ambiente. Para o professor S6, “[...] foi visível a mudança de pensamento; acredito que muitas mudanças de atitudes ocorram ao longo do tempo, percebi comentários positivos dos alunos a respeito dos projetos"; de acordo com o professor, alguns alunos falavam em separar o lixo das suas casas, para que, quando a administração municipal começasse a fazer a sua parte, ou seja, a coleta seletiva, eles já estivessem preparados. 
Foi consenso entre os professores participantes da formação que a matemática contribuiu para o interesse e para as preocupações dos alunos com as questões ambientais, pois foi uma ferramenta indispensável que trouxe muita informação, fê-los agir conscientemente e sensibilizou para mudanças de comportamento, na busca de um mundo mais sustentável.

Segundo os PCNs (2000), o conhecimento matemático formalizado precisa ser necessariamente transferido, e isso é possível pela contextualização desse saber. Essa contextualização pode atuar como ação motivadora da aprendizagem quando o professor dá significado a um conceito que pertence à matemática formal ou quando traz um conteúdo de interesse ou que faça parte do contexto dos alunos, pois são mostradas a importância do assunto que está sendo estudado e suas aplicações, motivando para aprender.

De acordo com os professores, as questões ambientais dependeram de conteúdos matemáticos para serem interpretadas. Assim, os alunos se aproximaram da matemática, contextualizando-a a partir da temática ambiental, ou seja, aconteceram transferências e ampliações de aprendizagens tanto dos conteúdos matemáticos como das problemáticas ambientais evidenciadas nos últimos tempos.

Ainda, segundo os professores, a matemática desempenhou o papel de dar subsídios para interpretação de fatos que ocorrem ao nosso redor, como é o caso das questões que permeiam a temática ambiental encontradas nas atividades desenvolvidas pelos alunos. Dessa forma, foi possível trabalhar nas aulas com os conteúdos de matemática, não permitindo que a transversalidade do tema meio ambiente entre as disciplinas envolvidas nos projetos e o tratamento das questões ambientais deixassem de ser o eixo central de estudo.

As características da interdisciplinaridade foram evidenciadas pela integração de ideias, ferramentas, linguagens, regras e conceitos das diferentes disciplinas envolvidas. Nas práticas escolares estruturadas previamente na formação dos professores, foram incorporadas as especificidades de cada escola, de cada sujeito envolvido (alunos, professores e pais), da realidade da comunidade, sem perder o foco de cada disciplina, que era desenvolver os conteúdos por meio de projetos interdisciplinares, visando ao desenvolvimento da consciência ambiental dos envolvidos.

As atividades de ensino devem promover aprendizagens mais significativas e funcionais possíveis, que tenham sentido e desencadeiem uma atitude favorável para realizá-las, que permitam o maior número de relações entre os distintos conteúdos, que constituam as estruturas de conhecimento, por um lado. Por outro, devem facilitar a compreensão de uma realidade que nunca se apresenta compartimentada. Isso os permite afirmar que a forma como os conteúdos são organizados tende para um enfoque globalizador (COLL, 2006, p. 186). 
Com a aplicação do Questionário 2 aos professores, percebeu-se com os depoimentos escritos que, de forma unânime, os professores declararam que a participação na formação em educação ambiental lhes deu subsídios para o trabalho com a temática ambiental nas aulas de matemática. Os educadores destacaram que, nos encontros realizados, foi possível, pela primeira vez, formar grupos de estudos e de pesquisa no município para: discutir temas referentes à educação matemática e à ambiental; trocar ideias; construir conhecimentos novos e atividades matemáticas aplicáveis em sala de aula envolvendo temas ambientais; e, principalmente, refletir sobre a própria prática.

O educador matemático dá outro significado a sua prática por meio da reflexão e de um ensino reflexivo, pois com sua experiência o professor transforma sua prática em um ensino mais concreto e significativo, estabelecendo novas relações com a disciplina. Formações continuadas que apresentam opções teóricas e metodológicas baseadas apenas na transmissão de conhecimentos e de experiências sem reflexões não garantirão o envolvimento dos professores e, consequentemente, não alcançarão os resultados desejados.

Os professores necessitam ser formados na perspectiva de profissionais reflexivos, e esse processo de reflexão sobre a prática se dá, conforme Schön (2000), pela reflexão na ação (simultaneamente à prática) e sobre a ação (acontecimentos dos momentos vividos).

Segundo Freire, "[...] na formação permanente dos professores, o momento fundamental é o da reflexão crítica sobre a prática. É pensando criticamente a prática de hoje ou de ontem que se pode melhorar a próxima prática” (1996, p. 43).

A ideia é de conceder espaço e oportunidade ao professor, para que ele possa se expressar e refletir em grupo sobre seus pensamentos, o que é de extrema importância numa formação continuada. O professor de matemática, envolvido numa ação de formação continuada, questiona a sua própria atuação e aprende saberes e práticas de outros professores, ainda tem a possibilidade de expor suas vivências profissionais, discutir com seus pares e, assim, produzir novos significados com essa troca. Logo, junto com a prática reflexiva, o trabalho colaborativo é mais um elemento significativo em uma formação de professores, para o desenvolvimento profissional do professor de matemática.

Com a formação, todos os professores concluíram que é possível e necessário trabalhar com educação ambiental nas aulas de matemática. Para eles, mesmo no princípio, quando o trabalho com temas ambientais foi complexo e difícil devido à falta de formação na área, a temática foi mais uma maneira de contextualizar a matemática, dando sentido aos conteúdos e envolvendo os alunos na construção do 
conhecimento, utilizando dados da realidade na prática de sala de aula. O professor S1 confirma essa conclusão, quando argumenta que:

[...] assim como eu, muitos professores procuram trabalhar a matemática de uma forma mais atraente e com exemplos práticos do cotidiano. E com a realização dos projetos pude alcançar este objetivo, tornando as minhas aulas mais significativas para os alunos [...] muitos alunos chegaram a pensar que não estavam estudando matemática, pois analisavam gráficos e tabelas, interpretavam problemas com dados matemáticos locais e regionais [...] (Professor S1).

Após a aplicação dos projetos elaborados na formação em suas aulas, os professores também declararam que continuarão promovendo essa integração de conhecimentos ampliando a relação entre educação matemática e educação ambiental, pois é possível dar um novo olhar para a matemática e contribuir com a conscientização ambiental dos alunos. Para muitos professores, o fato de conseguirem utilizar informações da região, do município e do bairro em que os alunos vivem, transformá-la em ferramenta de trabalho para as aulas, obtendo tabulações, construção de gráficos, cálculos de áreas, jogos matemáticos, situações-problema diversas, envolvendo os conteúdos, e ainda auxiliar no processo de desenvolvimento da cidadania dos alunos é de imprescindível importância.

A capacitação em educação ambiental precisa levar, inicialmente, o professor de matemática a repensar a sua relação com o meio, para assumir uma postura de mudança de valores pessoais que sejam incorporados nas práticas pedagógicas. $\mathrm{Na}$ formação continuada, ele precisa reconhecer que é protagonista de um processo formativo que não acabou na graduação e que ensinar está atrelado a sua relação com a disciplina lecionada e com sua maneira na condução das aulas.

É preciso repensar a formação continuada, para que ela viabilize aos professores uma reflexão sobre a associação teoria-prática, possibilitando o desenvolvimento profissional do professor no próprio local de trabalho. Conforme Behrens,

[...] o professor nesta busca de formação continuada deve ser caracterizado por um novo papel que contemple os seguintes desafios: uma ruptura com o individualismo pedagógico, ou seja, em que o trabalho e a reflexão em equipe se tornam necessários; uma análise científica da prática, permitindo desenvolver, com uma formação de nível elevado, um estatuto profissional, um profissionalismo aberto, isto é, em que o ato de ensino é precedido de uma pesquisa de informações e de um diálogo entre os parceiros interessados (1996, p. 134).

Propostas de formação isoladas e fragmentadas podem até mobilizar um grande número de professores, porém esses profissionais se limitarão a apenas sentar, ouvir e repetir as propostas sugeridas, sem questionamentos e reflexões, dificultando a implantação do conjunto de ações pedagógicas sugerido pelos órgãos responsáveis pelas formações de professores. 


\section{Considerações finais}

A transversalidade do tema meio ambiente sugerida pelos PCNs, com conteúdos trabalhados nas diversas disciplinas escolares, é uma forma de estabelecer um novo diálogo em sala de aula, pois o ensino valoriza os saberes extraescolares e suas possíveis relações com o currículo formal da escola.

O desenvolvimento desta pesquisa mostrou a relevância de trabalhos que envolvem educação matemática e educação ambiental na formação continuada de professores de matemática. Essa interligação é importante para instrumentalizar os professores a relacionar os conteúdos a serem desenvolvidos com a realidade dos alunos e possibilitar que todos possam lutar por mudanças sociais, ambientais, e políticas, ao tornarem-se construtores de seus conhecimentos. Trabalhar dessa forma confere à aprendizagem significado, pois os alunos conseguem estabelecer vínculos entre o que conhecem e os conteúdos novos a serem aprendidos. Além disso, esse trabalho possibilita sensibilizar os estudantes sobre a importância dos cuidados com o meio ambiente, transformando-os em alunos-cidadãos, conscientes da importância da preservação da natureza.

\section{Nota}

1 Disponível em: <http://ebooks.pucrs.br/edipucrs/anais/anais-do-egem/\#/artigos/2015/gtx>. Acesso em: 12 jan. 2017.

2 Primeira Hora, edição de 2015, p. 31.

\section{Referências}

BEHRENS, M. A. Formação continuada de professores e a prática pedagógica. Curitiba: Editora Universitária Champagnat, 1996.

BRASIL. Ministério da Educação. Secretaria de Educação Fundamental. Parâmetros Curriculares Nacionais: Meio Ambiente, Saúde. Brasília, DF: MEC/SEF, 1997.

BÚRIGO, R. Integração entre educação matemática e educação ambiental: uma proposição no contexto da gestão do conhecimento. Tese (Doutorado em Engenharia e Gestão do conhecimento) - Universidade Federal de Santa Catarina, Florianópolis, 2009.

CARVALHO, L. M. de. A educação ambiental e a formação dos professores. In: BRASIL. Ministério da Educação. Secretaria de Educação Fundamental. Panorama da educação ambiental no ensino fundamental. Brasília: MEC/SEF, 2001.

CARVALHO, I. C. de M. Educação ambiental a formação do sujeito ecológico. São Paulo: Cortez, 2012. 
CIFUENTES, J. C.; PRESTINI, S. A. M. M. A transversalidade e a educação matemática. In: MENEGHETTI, R. C. G. (Org.). Educação matemática: vivências refletidas. São Paulo: Centauro, 2006. p. 35-55.

COLL, C. O construtivismo na sala de aula. São Paulo: Ática, 2006.

COSTA, R. G. A. Um olhar crítico sobre a educação ambiental na formação de professores em uma instituição de ensino superior gaúcha. Revista Eletrônica do Mestrado em Educação Ambiental, Rio Grande, v. 22, p. 177-187, jan./jul. 2009.

D’AMBRÓSIO, U. Transdisciplinaridade. São Paulo: Palas Athena, 1997.

ELLIOTT, J. Recolocando a pesquisa-ação em seu lugar original e próprio. In: GERALDI, C.; FIORENTINI, D.; PEREIRA, E. M. de A. (Org.). Cartografias do trabalho docente: professor(a) pesquisador(a). Campinas: Mercado de Letras, 1998. p. 153-182.

FREIRE, P. Pedagogia da autonomia. São Paulo: Paz e Terra, 1996.

GHEDIN, E.; LEITE, Y. U. F.; ALMEIDA, M. I. de. Formação de professores: caminhos e descaminhos da prática. Brasília, DF: Líber Livro, 2008.

GUIMARÃES, M. Educação ambiental: no consenso um debate? Campinas: Papirus, 2000.

HERNÁNDEZ, F.; VENTURA, M. A organização do currículo por projetos de trabalho: o conhecimento é um caleidoscópio. Porto Alegre: ArtMed, 1998.

LIMA, G. F. C. Educação Ambiental crítica: do socioambientalismo às sociedades sustentáveis. Educação e Pesquisa, São Paulo, v. 35, n. 1, p. 145-163, jan./abr. 2009.

LÜDKE, M. A complexa relação entre o professor e a pesquisa. In: ANDRÉ, M. (Org.). O papel da pesquisa na formação e na prática dos professores. Campinas: Papirus, 2001. p. 27-54.

LOUREIRO, C. F. B. Trajetória e fundamentos da educação ambiental. São Paulo: Cortez, 2004.

PENTEADO, H. D. Meio ambiente e formação de professores. São Paulo: Cortez, 2010.

SCHÖN, D. Educando o profissional reflexivo: um novo design para o ensino e a aprendizagem. Porto Alegre: ArtMed, 2000.

SKOVSMOSE, O. Towards a philosophy of critical mathematics education. New York: State University of New York Press, 1994.

ZABALZA, Miguel A. O ensino universitário: seu cenário e seus protagonistas. Porto Alegre: ArtMed, 2004. 